\title{
Analisis Natrium dalam Air Laut Di Sekitar Pesisir Pantai Papua dengan Metode Spektroskopi Serapan Atom
}

\author{
Yoice Martina Paweka \\ Pemerintah Daerah Tingkat I Propinsi Papua, Jl. Soa Siu Dok II Jayapura - Papua \\ E-mail : joiceymp@gmail.com
}

\begin{abstract}
Abstrak
Menurut Kementerian Perikanan dan Kelautan pada tahun 2014, luas lahan garam di Indonesia adalah 28.556 ha. Kebutuhan garam per tahun sekitar 3,5 juta ton sehingga untuk menutupi kebutuhan dilakukan impor garam dari beberapa negara. Propinsi Papua terletak pada koordinat 130 - 140 BT dan 9,0 - 10,45 LS dengan garis pantai sepanjang 1.170 mil laut. Air laut mengandung $86 \%$ natrium klorida $(\mathrm{NaCl})$. Metode penelitian yang dilakukan secara eksperimental di laboratorium dengan menggunakan instrumen spektrofotometer serapan atom (SSA) karena selektif, spesifik, sensitivitas tinggi dalam kisaran ppm sampai ppb. Hasil kadar natrium dari air laut pada tujuh lokasi pantai di propinsi Papua sebagai berikut: pantai Kali Maro Onggalie Merauke 87,4 \pm 1 ppm, pantai Lampu Satu Merauke $112 \pm 0,6$ ppm, pantai Payum Merauke 103,2 \pm 0,6 ppm, pantai Pasir Dua Jayapura 91,3 \pm 1,7 ppm, patai Ria Base G Jayapura 88,3 \pm 0 ppm, pantai Dok II Jayapura 88,7 $\pm 1,5$ ppm dan pantai Hamadi Jayapura 106,4 \pm 2 ppm. Rentang hasil kadar natrium antara 88,3 \pm 0 ppm sampai $112 \pm 0,6$ ppm. Disimpulkan bahwa kadar natrium dari pesisir pantai Papua dapat berpotensi sebagai sumber bahan baku garam farmasi.
\end{abstract}

Kata kunci: hipertensi, spektroskopi emisi nyala, garam farmasi, garam diet, laut

\section{PENDAHULUAN}

Potensi sumber daya laut (hayati dan non hayati) di kawasan kedaulatan NKRI dengan panjang garis pantai $95.181 \mathrm{Km}$ dan luas laut $5,800.000 \mathrm{Km}^{2}$ (Boy Rahardjo Sidharta, 2016). Sumberdaya tersebut dibagi dalam sumberdaya terbarukan (renewable resources), seperti perikanan dan hutan mangrove, dan sumberdaya tidak terbarukan (non renewable resources), seperti batu bara, minyak dan gas bumi, dan bahan tambang. (La. Sara, 2014). Air laut mengandung $86 \%$ natrium klorida (NaCl) (James Murray, 2004). Natrium mempunyai peran penting dalam keseimbangan cairan, kontraksi otot, sistem saraf, dan berperan dalam distribusi cairan tubuh. Konsentrasi ion natrium dalam plasma (ekstraseluler) adalah 130-145 mmol/L (Shah et al., 2011). Propinsi Papua, terletak pada koordinat 130 140 BT dan 9,0 - 10,45 LS, dengan panjang garis pantai sepanjang 1.170 mil laut, di dalamnya mengandung berbagai jenis biota laut yang bernilai ekonomis penting, termasuk potensi lahan untuk pengembangan budidaya laut dan tambak (Profil Dinas Kelautan dan Perikanan Propinsi Papua. Diakses pada tanggal 22 September 2016).

Sampel air laut yang diambil secara random. Pengambilan sampel merupakan masalah yang sangat penting dalam analisis kimia sebab untuk mengetahui kadar atau konsentrasi suatu senyawa tertentu dalam sampel hanya dilakukan terhadap sejumlah kecil sampel. Oleh karena itu, cara pengambilan sampel yang salah meskipun metode analsisnya tepat dan teliti hasilnya tidak akan memberikan petunjuk yang benar mengenai sifat (dalam hal ini kadar) yang akan diteliti. Pengambilan sampel pada tesis ini dilakukan dengan cara pengambilan sampel random (cuplikan random, cuplikan acak) yaitu cara pengambilan sampel dilakukan terhadap bahan yang serba sama (homogen) misalnya larutan sejati, batch tablet, ampul dan sebagainya. Untuk dapat disampel secara random, sampel harus terlebih dahulu digerus secara homogen. Begitu pula larutan/suspensi harus digojog sampai homogen, lalu dilakukan pengambilan sampel secara random (Gandjar Gholib Ibnu dan Rohman Adul, 2007).

Kadar natrium dan kalium dari sampel air laut, dihitung berdasarkan persamaan kurva baku (regresi), untuk natrium 100-500 ppm dan kalium 10-50 ppm. Regresi merupakan kurva yang menyatakan hubungan antara dua besaran. Contoh regresi sederhana adalah hubungan antara konsentrasi dengan absorbansi pada spektrofotometri. Hubugan antara kedua besaran dapat dilukiskan $\mathrm{y}=\mathrm{bx}+\mathrm{a}, \mathrm{y}=$ menyatakan absorbansi, $\mathrm{x}=$ konsentrasi, $\mathrm{b}=$ koefisien regresi (juga menyatakan slope = kemiringan), $a$ = tetapan regresi dan juga disebut intersep (Gandjar Gholib Ibnu dan Rohman Adul, 2007).

Air laut adalah cairan yang bersifat agak basa $(\mathrm{pH}$ $7,5-8,4)$ yang merupakan campuran lebih dari 80 unsur, gas dan senyawa organik terlarut. Konsentrasi campuran unsur-unsur tersebut beragam dan berbeda tergantung pada faktor tempat (geografis) dan fisik pengukuran salinitas air laut dalam ppt (\%) yang menunjukkan konsentrasi senyawa terlarut. Ion-ion utama penyusun air laut adalah: natrium 55\%, klor 31\%, sulfat $8 \%$, magnesium $4 \%$, kalsium $1 \%$ dan kalium $1 \%$. Laut di garis lintang subtropis memiliki salinitas tertinggi sebagai akibat dari suhu yang lebih tinggi, sedanng laut di kawasan sedang (temperate) memiliki salinitas lebih rendah karena rendahnya evaporasi. Laut terbuka memiliki salinitas tetap dengan kisaran $34-37 \%$, dengan 
perbedaan kelarutan akibat curah hujan dan evaporasi. Kawasan tertutup seperti laut Merah dan Teluk Ara, memiliki saliitas 44\%. (Boy Rahardjo Sidharta, 2016)

Penguapan air adalah faktor yang signifikan dalam meningkatkan tingkat natrium selama musim panas. Seperti natrium, kalium juga merupakan elemen alami, tetapi konsentrasinya lebih rendah dari natrium dan kalsium (Wetzel, 2000).

Menurut Desrosier (1988) dalam Amalia (2007), ada tiga sumber utama garam, yaitu :

1. Garam solar ialah garam yang diperoleh dengan cara penguapan dari air garam baik yang dari laut maupun yang dari danau garam daratan.

2. Tambang garam atau garam sumber ialah garam yang biasanya dinyatakan sebagai batu garam, diperoleh dari pertambangan yang beroperasi sedalam seribu kaki atau lebih dibawah permukaan bumi.

3. Garam yang diperoleh dari penguapan dengan sinar matahari mengandung kotoran kimia dan mikrobia halofisilis yang toleran terhadap garam. Garam tambang atau garam sumber pada umumnya bebas dari kontaminasi organisme ini.

Di Bengaluru Karnataka India, dalam Jurnal International Journal of Advanced Research (2015) volume 3 edisi 7, diperoleh konsentrasi natrium berkisar antara $60.40 \mathrm{mg} / \mathrm{L}$ untuk $106.20 \mathrm{mg} / \mathrm{L}$ dan kalium antara $7.2 \mathrm{mg} / \mathrm{L}-11.9 \mathrm{mg} / \mathrm{L}$. Konsentrasi tinggi natrium tercatat selama pre monsoon (musim panas) musim dan konsentrasi terendah tercatat selama south west monsoon musim (hujan).

Di Tamil Nadu India dalam Jurnal Bhuna et al. Int. J Res. Chem Environ Vol 2. Issue 3 Juli 2012, diperoleh rentang konsentrasi natrium 36-2305 ppm dan konsentrasi kalium 1-39 ppm, dapat dilihat pada gambar 4.2.Menurut Solanki (2001), volume tertinggi natrium selama musim panas adalah karena penyusutan volume air.

\section{METODE}

Penelitian dilakukan secara eksperimental di laboratorium melalui beberapa tahapan yaitu:

1. Pengumpulan Sampel

Pengumpulan sampel dari air laut pada tujuh lokasi pantai di propinsi Papua yaitu: Pantai Kali Maro Onggalie Merauke dengan lokasi google maps: Attitude: -8.306588 LS; Longitude: 140.134639 BT, Pantai Lampu Satu Merauke dengan lokasi google maps: Attitude: -8.498986 LS; Longitude: 140.369527 BT, Pantai Payum Merauke, dengan lokasi google maps: Attitude: -8.547181 LS; Longitude: 140.418960 BT, Pantai Pasir Dua Jayapura dengan lokasi google maps: Attitude: 2.507536 LS; Longitude: 140.734352 BT, Pantai Ria Base G Jayapura dengan lokasi google maps: Attitude: -2.517035 LS; Longitude: 140.749309 BT, Pantai Dok II Jayapura dengan lokasi google maps: Attitude: -2,536278 LS; Longitude: 140.717088 BT,
Pantai Hamadi Jayapura dengan lokasi google maps: Attitude: -2.577589 LS; Longitude: 140.709180 BT. Pengumpulan sampel dilakukan dengan metode simple random sampling di dalam botol plastik sebanyak $200 \mathrm{ml}$, yang sebelumnya telah dibilas dengan $\mathrm{HNO}_{3}$ 0,02 $\mathrm{M}$.

2. Penyiapan Alat dan Penetapan Kinerja Harian Dilakukan pengukuran terhadap serapan emisi larutan baku natrium $\mathrm{NaNO}_{3}$ dalam $\mathrm{HNO}_{3}$ 0,5 mol/l $1000 \mathrm{mg} / \mathrm{l} \mathrm{Na}$. Dihitung akurasi dan presisi dengan mengukur 5 variasi konsentrasi yaitu 100, 200, 300, 400 dan 500 ppm sebanyak 3 kali

3. Validasi Metode Analisis

a) Linearitas

Membuat 5 variasi konsentrasi yaitu 100, 200, 300, 400 dan 500 ppm untuk larutan baku natrium $\mathrm{NaNO}_{3}$ dalam $\mathrm{HNO}_{3}$ 0,5 mol/l $1000 \mathrm{mg} / \mathrm{l} \mathrm{Na}$. Masing-masing larutan diukur emisi dan diplotkankan antara konsentrasi terhadap emisi untuk mendapatkan kurva baku.

b) Kecermatan (accuracy)

Uji ini dilakukan dengan membuat 5 variasi konsentrasi yaitu 100, 200, 300, 400 dan 500 ppm untuk larutan baku natrium $\mathrm{NaNO}_{3}$ dalam $\mathrm{HNO}_{3}$ 0,5 mol/l $1000 \mathrm{mg} / \mathrm{l} \mathrm{Na}$, yang kemudian masingmasing konsentrasinya diukur sebanyak 3 kali pengulangan. Serapannya dicatat dan kadarnya dihitung dengan menggunakan persamaan kurva baku, kemudian dihitung uji perolehan kembalinya.

c) Keseksamaan (precision)

Uji ini dilakukan dengan membuat 5 variasi konsentrasi yaitu 100, 200, 300, 400 dan 500 ppm untuk larutan baku natrium $\mathrm{NaNO}_{3}$ dalam $\mathrm{HNO}_{3}$ 0,5 mol/l $1000 \mathrm{mg} / \mathrm{l} \mathrm{Na}$ dan, yang kemudian masing-masing konsentrasinya diukur sebanyak 3 kali pengulangan. Serapannya dicatat dan kadarnya dihitung dengan menggunakan persamaan kurva baku, kemudian dihitung simpangan baku.

c) Batas Deteksi (limit of detection)

Uji ini dilakukan dengan menghitung simpangan residual dari persamaan kurva linier. Batas deteksi ditentukan dengan mencari konsentrasi yang memberikan intensitas 3 kali dari intensitas respon blanko.

d) Batas Kuantitasi (limit of quantification)

Uji ini dilakukan dengan menghitung simpangan residual dari persamaan kurva linier. Batas kuantitasi ditentukan dengan mencari konsentrasi yang memberikan intensitas 10 kali dari intensitas respon blanko $(\mathrm{ICH}, 1994)$

4. Penetapan kadar Natrium

Preparasi Larutan Standar

a) Larutan baku natrium $\mathrm{NaNO}_{3}$ dalam $\mathrm{HNO}_{3} 0,5$ $\mathrm{mol} / \mathrm{l} 1000 \mathrm{mg} / \mathrm{l} \mathrm{Na}$

b) Membuat 5 variasi konsentrasi yaitu 100, 200, 300, 400 dan 500 ppm. 
Preparasi sampel

a) Sampel berupa air laut dalam wadah botol plastik sebanyak $200 \mathrm{ml}$.

b) Sampel air laut dipipet $1 \mathrm{ml}$ dipindahkan kedalam labu ukur $100 \mathrm{ml}$, ditambah $2 \mathrm{ml} \mathrm{HNO}_{3}$ $0,02 \mathrm{M}$ lalu kemudian ditambah aquadest hingga tanda batas.

Pengukuran pada alat spektroskopi serapan atom

a) Unit spektroskopi serapan atom diaktifkan kemudian dilakukan pengukuran absorbansi blanko dengan 3 kali pengukuran.

b) Dilakukan pengukuran absorbansi untuk 5 variasi larutan standar

c) Dilakukan pengukuran absorbansi larutan sampel.

d) Data yang diperoleh kemudian disimpan sesuai nama sampel.

\section{Uji Statistika}

Data yang diperoleh dianalisis dengan menggunakan metoe ssatistik Pearson's product moment correlation. Metode ini digunakan untuk melihat keterkaitan antaara dua varriabel, dan biasanya hanya digunakan untuk data-data yang numerik dan absolut. Kriteria penerimaannya adalah $\mathrm{p}$-value $<0.05$

\section{HASIL}

Hasil kadar natrium dari air laut pada tujuh lokasi pantai di propinsi Papua sebagai berikut: pantai Kali Maro Onggalie Merauke 87,4 \pm 1 ppm, pantai Lampu Satu Merauke $112 \pm 0,6$ ppm, pantai Payum Merauke $103,2 \pm 0,6$ ppm, pantai Pasir Dua Jayapura 91,3 $\pm 1,7$ ppm, patai Ria Base G Jayapura 88,3 \pm 0 ppm, pantai Dok II Jayapura 88,7 $\pm 1,5$ ppm dan pantai Hamadi Jayapura 106,4 \pm 2 ppm. Rentang hasil kadar natrium antara 88,3 \pm 0 ppm sampai $112 \pm 0,6$ ppm.

Kadar natrium dapat dilihat dalam tabel dan gambar sebagai berikut:

1. Kadar natrium

2. Pemetaan Lokasi sampling untuk kadar natrium dan kalium di Jayapura

3. Pemetaan Lokasi sampling untuk kadar natrium dan kalium di Merauke

Pemaparan hasil kadar natrium dari 7 lokasi sampling di Papua berkaitan dengan cekungan air tanah. Berdasarkan pustaka, air tanah mengalir di daerah CAT sebagai soil water dan groundwater. Groundwater zone ini disebut sebagai cekungan air tanah (CAT) (Robert J. Kodoatie, 2012).

Cekungan air tanah adalah suatu wilayah yang dibatasi oleh batas hidrogeologis, tempat semua kejadian hidrogeologis seperti proses pengimbuhan, pengaliran, dan pelepasan air tanah berlangsung. Daerah imbuhan air tanah adalah daerah resapan air yang mampu menambah air tanah secara alamiah pada cekungan air tanah. Daerah lepasan air tanah adalah daerah keluaran air tanah yang berlangsung secara alamiah pada cekungan air tanah. Air tanah adalah air yang terdapat dalam lapisan tanah atau batuan di bawah permukaan tanah. Akuifer adalah lapisan batuan jenuh air tanah yang dapat menyimpan dan meneruskan air tanah dalam jumlah cukup dan ekonomis (PP No.43 tahun 2008 pasal 1 ayat $1-5$ tentang air tanah).

Cekungan air tanah yang selanjutnya disingkat CAT adalah suatu wilayah yang dibatasi oleh batas hidrogeologis, tempat semua kejadian hidrogeologis, seperti proses pengimbuhan, pengaliran, dan pelepasan air tanah berlangsung (PP No.32 tahun 2015 tentang rencana tata ruang kawasan perbatasan negara di propinsi Papua, ayat 11)

Untuk garam proanalisis dan garam farmasi, mempunyai kandungan $\mathrm{NaCl}>99 \%$, garam konsumsi mempunyai kandungan $\mathrm{NaCl}>94 \%$ dan garam untuk pengawetan memiliki kandungan $\mathrm{NaCl}>90 \%$. (Rismana, 2004). Hasil kadar natrium dari air laut pada tujuh lokasi pantai di propinsi Papua sebagai berikut: pantai Kali Maro Onggalie Merauke 87,4 \pm 1 ppm, pantai Lampu Satu Merauke $112 \pm 0,6$ ppm, pantai Payum Merauke 103,2 \pm 0,6 ppm, pantai Pasir Dua Jayapura 91,3 \pm 1,7 ppm, patai Ria Base G Jayapura 88,3 \pm 0 ppm, pantai Dok II Jayapura 88,7 $\pm 1,5$ ppm dan pantai Hamadi Jayapura 106,4 \pm 2 ppm., menunjukkan hasil yang masuk dalam persyaratan garam proanalisis dan garam farmasi, garam konsumsi dan garam untuk pengawetan.

Para ilmuwan telah mempelajari air laut, mereka telah berhasil menguraikan berbagai unsur garam yang terlarut dan menghitung perbandingannya. Unsurunsur ini terdiri dari: klorida $55 \%$, natrium $30,6 \%$, sulfat $7,7 \%$, magnesium 3,7\%, kalsium 1,2\%, kalium 1,1\%, bikarbonat 0,4\%, bromida 0,2\%. (Mengapa Air Laut Asin Perpustakaan Online. (Diakses tanggal 27 Agustus 2015)

Kadar natrium dan kalium di pantai Kali Maro Merauke, pantai Lampu Satu Merauke, pantai Payum Merauke, memberikan hasil yang baik, hal ini dipengaruhi oleh sumberdaya lahan. Suatu lahan dapat memiliki potensi sumber daya geologi yang besar (sumber daya air, bahan galian, mineral industri, sumber daya energi, dll). Sumberdaya lahan adalah lahan yang didalamnya mengandung semua unsur sumber daya, baik yang berada diatas maupun dibawah permukaan bumi. Faktor-faktor yang menentukan sumber daya lahan adalaha: ketinggian/elevasi, kelerengan, jenis batuan, jenis tanah, tutupan lahan, hidrologi, fauna dan flora, iklim dan posisi geografis, bencana alam. Salah satu faktor yaitu ketinggian/elevasi di Merauke, Ketinggian suatu lahan diukuur/dihitung dari tinggi muka air laut rata-rata, yaitu harga rata-rata tinggi air laut pasang dan tinggi air laut surut. Di dunia ini pasang surut air laut sangat bervariasi dan hal ini sangat ditentukan oleh posisi geografis dimana lahan tersebut berada. Sebagai contoh pasang surut air laut di Merauke Papua bisa mencapai puluhan kilometer ke arah daratan, sedangkan di pulau Jawa pasang surut air laut mencapai beberapa meter hingga ratusan meter ke arah daratan. 
Berdasarkan lokasinya, lahan dapat dikelompokkan ke dalam lahan pasang surut, lahan pantai, lahan basah, lahan kering, lahan dataran rendah, lahan dataran tinggi, lahan perbukitan, dan lahan pegunungan (Noor Djauhari, 2006).

Pengetahuan mengenai batuan (petrologi), diperlukan untuk mendapatkan berbaga jenis mineral logam. Kelompok batuan tersusun dari berbagai jenis mieral dan mineral tersusun dari berbagai jenis unsur kimia (Noor Djauhari, 2006).

Batuan memberikan pengaruh yang signifikan terhadap sumber daya air, baik dari sisi sumber air, daya air maupun keberadaan air. Pada bagian dasar groundwater ada kontak antara air dan batuan yang memberikan pengaruh kimiawi terhadap air sehingga kandungan kimia air yang mengalir akan mengalami evolusi sesuai dengan lokasi aliran air. Terhadap air asin yang bermuara di laut maka aliran air tanah merupakan agen atau perantara geologi yang memberikan pengaruh secara terus menerus terhadap lingkungan di sekelilingnya di dalam bumi (Toth, 1984). Chebotarev (1955) menyimpulkan bahwa selama prses perjalanannya aliran air tanah cenderung mengubah secara perlahan komposisi kimia air yang ada dari hulu ke hilir dan mengarah pada komposisi kimia air laut. Unsur-unsur kimia yang larut dalam air tanah berjalan dan berevolusi lewat jalan aliran tanah. la menyelidiki bahwa evolusi ini diikuti oleh perubahan regional dari spesies anion yang dominan seperti terlukis pada diagaram dalam gambar 4.13 (Roberth J. Kodoatie, 2012).

Proses perjalanan air tanah dari hulu (gunung) ke hilir (laut).

1. Kadar Natrium

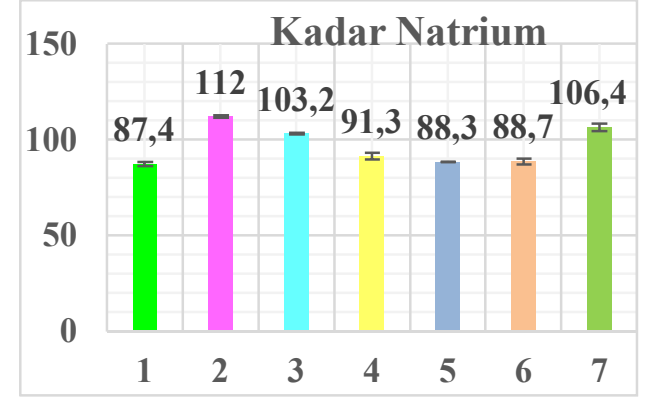

Gambar 1. Kadar Natrium

2.Pemetaan lokasi sampling untuk kadar natrium di Jayapura

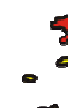

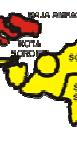
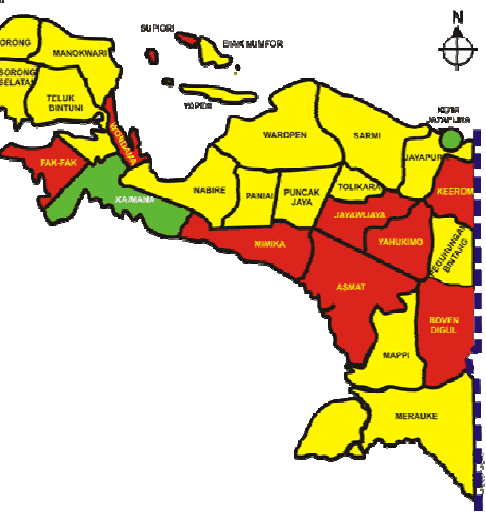

$\oplus$

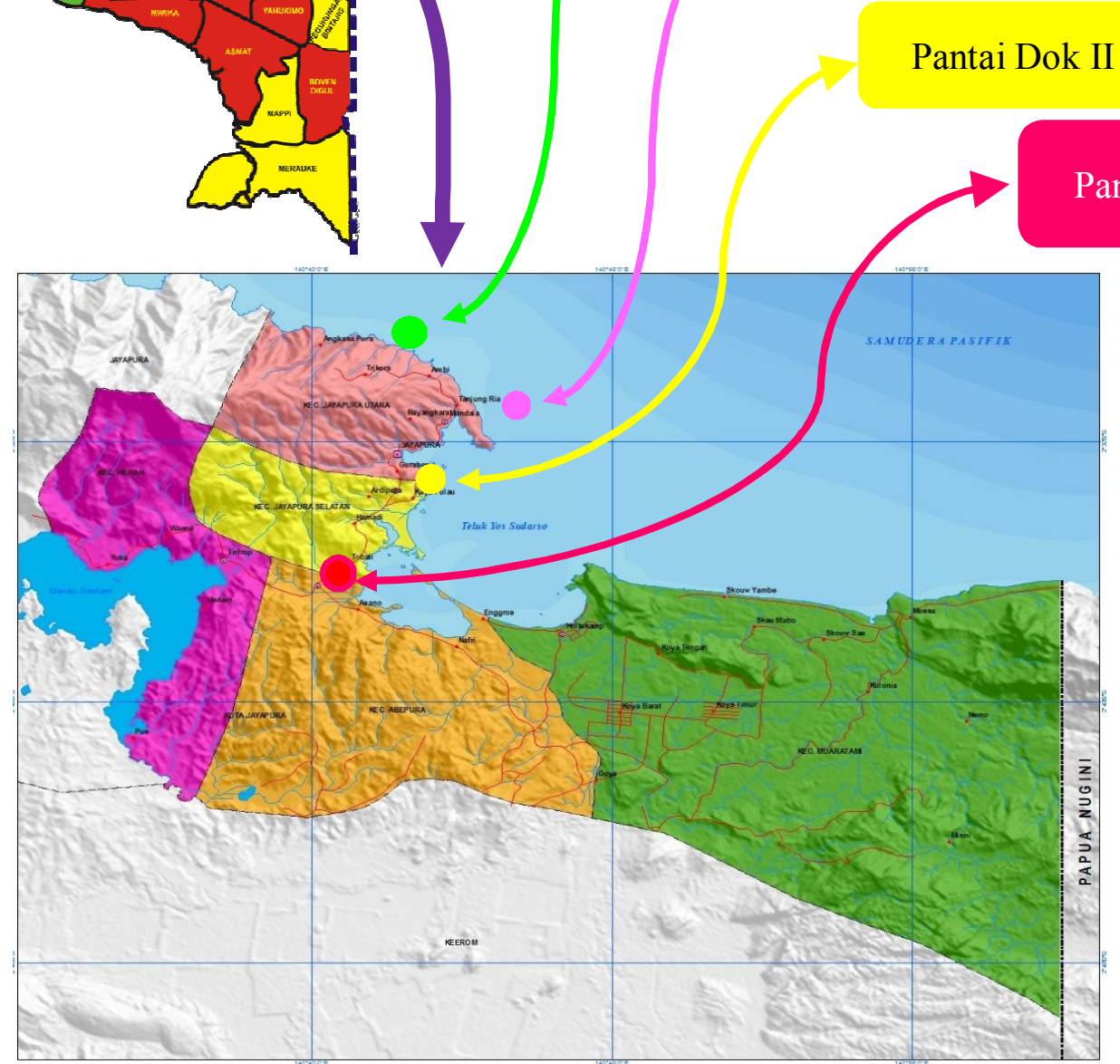

\section{Pantai Pasir Dua}

\section{Pantai Ria Base G}


3.Pemetaan lokasi sampling untuk kadar natrium di Merauke

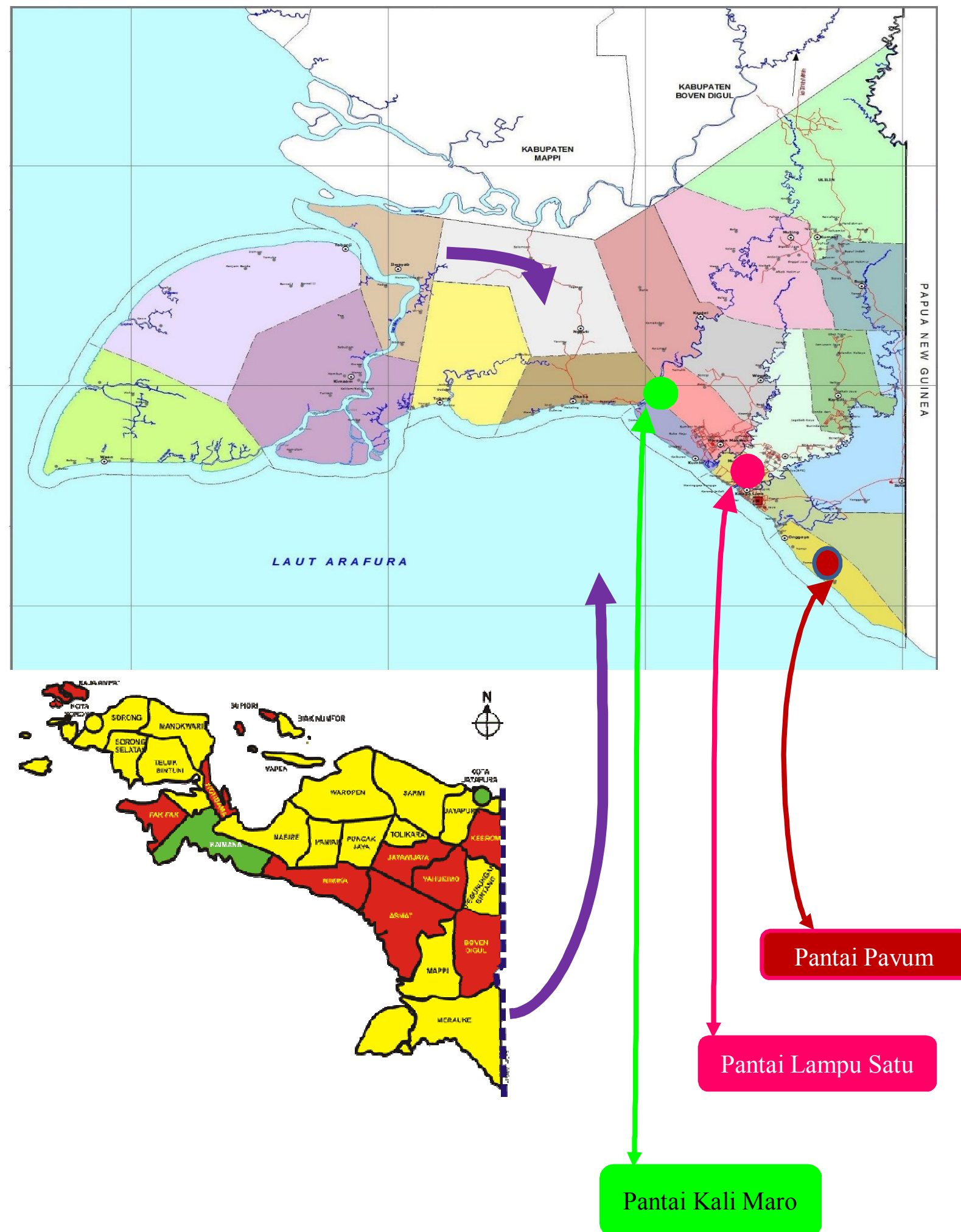




\section{SIMPULAN}

Kadar Natrium pada air laut di Pesisir Pantai Papua dapat berpotensi sebagai sumber bahan baku garam farmasi.

\section{PUSTAKA}

1. Arjana Bagus Gust I, 2013. Geografi Lingkungan. Jakarta: Penerbit PT Raja Grafindo Persada. Halaman: 54-73.

2. Barasi, M. 2009. Nutrition at A Glance. Penerjemahan: Hermin 2009 At A Glance: Ilmu Gizi. Jakarta: Penerbit Erlangga. Hal. 52.

3. Bheemappa K, dkk. 2015. Temporal Variation in Water Quality Parameters of Bandematta Hosakere Lake - Peri Urban Area of Bengaluru, Karnataka India, International Journal of Advanced Research Volume 3 Issue 7, 1283-1291.

4. Christian, G. D. 1994. Analytical Chemistry. $5^{\text {th }}$ edition. New York: John Wiley \& Sons, Inc, page 478-479.

5. Day, R.A and A.L. Underwood. 1986. Analisis Kimia Kuantitatif, Edisi ke-5. Penerjemah: Hadyana. Jakarta: Penerbit Erlangga. Hal 446-447

6. Desrosier. 1988. Teknologi Pengawetan Pangan. Jakarta: Universitas Indonesa Press.

7. Gandjar Gholib Ibnu dan Rohman Adul, 2007. Kimia Farmasi Analisis. Yogyakarta: Penerbit Pustaka Pelajar. Halaman: 31-32, 39-40

8. Harmita, 2004. Petunjuk Pelaksanaan Validasi Metode dan Cara Perhitungannya. Majalah IImu Kefarmasian, 1(3), 117-134, Departemen Farmasi FMIPA, Universitas Indonesia, Jakarta.

9. Harmita. 2006. Buku Ajar Analisis Fisiko kimia cetakan pertama. Cipta Kreasi Bersama. Jakarta. Halaman: 87-93, 144-156.

10. Kodoatie J Robert \& Sjarief Roestam, 2010. Tata Ruang Air, Penerbit ANDI, Yogyakarta. Halaman: 131-137.

11. Metcalfe, E. D. 1987. Atomic Absorption and Emission Spectroscopy. London: John Wiley \& Sons.

12. Munson James W, 1991. Analisis Farmasi - Bagian B, Penerjemah: Harjana, Penerbit Airlangga Universtity Press. Surabaya. Halaman: 321-322

13. Munoz Ramirez Juan, 1968. Atomic Absorption Spectroscopy and Analysis by Atomic-Absorption Flame Photometry, Elsevier Publishing Company, New York, Page: 17-19.

14. Noor Djauhari, 2006. Geologi Lingkungan. Jakarta: UIEU University Press. Halaman: 81, 98-100

15. Preeti Tiwari, Rajiv Chandak, R.K. Yadav, 2014. Effect of Salt Water o compresive Strength of
16. Mortar. International Journal of Emerging Trends in Engineering and Development. Issue 4, Vol.2 (March 2014) ISSN 2249-6149.

17. Profil Dinas Kelautan dan Perikanan Propinsi Papua. https://www.papua.go.id/view-detailpage-16/profil-dinas-kelautan-dan perikananprovinsi-papua.html. (Diakses pada tanggal 21 Juli 2015)

18. Puryono KS Sri. 2016. Mengelola Laut untuk Kesejahteraan Rakyat, Jakarta, PT Gramedia Pustaka Utama. 2-5, 82

19. Roth J Herman \& Blaschke Gottfried, 1985. Analisis Farmasi, Gadjah Mada University Press, Yogyakarta, Halaman: 378-379)

20. Sara La. 2014. Pengelolaan Wilayah Pesisir Gagasan Memeliharaa Aset Wilayah Pesisir dan Solusi Pembangunan Bangsa. Bandung: CV Alfabeta, Hal 1-3.

21. Sidharta Rahardjo Budi, 2016. Bioteknologi Kelautan, Yogyakarta: Cahaya Atma Pustaka, Halaman: 3-43, 65-66

22. Shah, K.V., P.K. Kapupara, T.R. Desai. 2011. Determination of Sodium, Potassium, Calcium and Lithium in A Wheat Grass by Flame Photometry. Online Published (2011). ISSN: 0976-7908

23. Skoog. D. A., Donald M. West, F. James Holler, Stanley R. Crouch, 2000. Fundamentals of Analytical Chemistry .Hardcover: 992 pages, Publisher: Brooks Cole

24. Skoog, D.A., D.M. West, F.J. Holler and S.R. Crouch. 1999. Analytical Chemistry: an Introduction, $\left(7^{\text {th }}\right.$ Ed.). Philadelphia: Sounders College, hal 594-631.

25. Suharman dan Mulja M. 1995. Analisis Instrumen. Surabaya: Airlangga University Press, hal 102-103.

26. Treman Wayan I 2014. Geomorfologi. Yogykarta: PT Graha Ilmu. Halaman: 56-73

27. UU N0. 27 tahun 2007 pasal 1 ayat 4

28. Wetzel, R.G. (2000). Limnology-Lake and River Ecosystems.3rdedition. Academic Press.

29. Winarno, F.G. 2004. Kimia Pangan dan Gizi. Jakarta: PT. Gramedia Pustaka Utama, hal 150-153.

30. Willard, H. H., Merrit, L; L., and Settle Jr, F. A., 1989, Instrumental Methods of Analysis, Wadsworth Publishing Company, 'California.

31. Prihatiningsih Tri. (2015). Analisa Kualitas Produksi Garam di CV. Mutiara Laut Biru . Program Studi Teknik Elektro, Fakultas Teknik, Universitas Panca Marga. Vol.5 No.2 ISSN: 2088-4591

32. Solanki, H.A. (2001). Study on pollution of soils and water reservoirs near industrial areas of Baroda. Ph.D. Thesis, Bhavnagar University. 